\title{
If a Red Horse is Red, is a Blue Horse Blue? Vincent Charles Villebrun
}

$\mathrm{W}$

hen it comes to education within prison settings, one of the biggest

benefits is the potential to raise the self-esteem of incarcerated men and women. There are also other benefits as education and vocational training programs broaden prisoners' opportunities to enter the workforce upon release. This can also improve their self-esteem and socio-economic status, and make it less likely that they will re-engage in crime. But when making this argument about education, I am distinguishing between two forms - the elementary/secondary system and the post-secondary system of education. These are more properly distinguished as the "banking" and the "problem-posing" systems of education respectively. According to Freire (1971, pp. 73-74), the banking-system of education is paternalistic and narrative in character.

This relationship involves a narrating Subject (the teacher) and patient, learning objects (the students)... The banking approach to adult education, for example, will never propose to students that they critically consider reality. It will deal instead with such vital questions as whether Roger gave green grass to the goat, and insist upon the importance of learning that, on the contrary, Roger gave green grass to the rabbit. The "humanism" of the banking approach masks the effort to turn women and men into automatons - the very negation of their ontological vocation to be more fully human.

The problem-posing system of education differs from the banking system insofar as the students are called upon to be cognitive, rather than to memorize what has been narrated by others. As Freire (1971, pp. 80-81) explains,

The problem-posing method does not dichotomize the activity of the teacher-student: she is not "cognitive" at one point and "narrative" at another. She is always "cognitive," whether preparing a project or engaging in dialogue with the students. He does not regard cognizable objects as his private property, but as the object of reflection by himself and the students. In this way, the problem-posing educator constantly re-forms his reflections in the reflection of the students. The students are no longer - docile listeners - but are now critical co investigators in dialogue with the teacher. ... Whereas banking education anesthetizes 
and inhibits creative power, problem-posing education involves a constant unveiling of reality. The former attempts to maintain the submersion of consciousness; the latter strives for the emergence of consciousness and critical intervention in reality.

Others, like Fromm (2010), would go further in denouncing the banking system of education as a system that not only does not allow for growth, but rather promotes social death. When considering parental direction as a banking system of education, this is a strong indictment of how much of our child rearing is at the root of societal ills.

When I was a child, I did not talk much. I was fairly confident that no one was interested in anything I had to say. I was raised to believe that I was worthless, which is how my adoptive parents shaped me. "You are a good for nothing, dirty little Indian, whose mother the squaw-whore gave away". "No-one will ever love you, you little bastard. You are not even good enough for a squaw-whore to love and that's why she gave you away". "Indians are to be seen and not heard". "You have a strong back, but a weak mind and you will never amount to anything". "You're a stupid, worthless, good-for-nothing Indian and we don't know why we adopted you". These were the banking deposits I often heard from them. I was not a person with the autonomy to develop my own identity. I was an object who had an identity imposed upon me by my oppressors. I was less than human. As a result of this, along with my introversion and hypersensitivity, I developed drug and alcohol issues, and a long suppressed anger, among many other negative emotions. I came to prison as a high-school dropout, with low selfesteem, and no concrete life-goals or direction. It seems obvious to me now where I was headed, but at the time, this was not apparent.

Mine was a transracial adoption from a Métis (Cree and French) home community of Green Lake, Saskatchewan to the suburban community of Surrey, British Columbia by a husband and wife who were secondgeneration Canadian born from Dutch-Russian-Welsh backgrounds. My experience of adoption was not unlike a form of "cultural invasion" as discussed by Freire (1971, p. 160): "cultural invasion, which serves the ends of conquest and the preservation of oppression, always involves a parochial view of reality, a static perception of the world, and the imposition of one world view upon another". As a member of a defeated society, having been invaded through a process of colonialism, my experience was of the 
colonized where I was made a ward of the state at birth, being adopted by a non-Indigenous family, and having their cultural context imposed on me. More than a cultural invasion, it was a cultural immersion and assimilation supported by the psychological and alcoholic abuse of my adoptive parents. Where Freire (1971, p. 153) argues that "all domination involves invasion", I would further argue that all invasion involves domination, along with cultural immersion and assimilation. The immersion and assimilation of a member of one culture into another assumes the dominance of the latter.

Cultural conquest leads to the cultural inauthenticity of those who are invaded [immersed and assimilated]; they begin to respond to the values, the standards, and the goals of the invaders [assimilators]. ... For cultural invasion [immersion and assimilation] to succeed, it is essential that those invaded [assimilated] become convinced of their own intrinsic inferiority. (Freire, 1971, p. 153).

In striving to talk "white", walk "white", dress "white" and act "white", I denied my ethnicity to anyone who asked if I was "native Indian". I struggled with feelings of inferiority and the belief that I was incapable of learning or ever amounting to anything. It created much emotional and internal conflict as I struggled with resisting the words of my adoptive parents about who and what I was, and where I came from, while at the same time becoming convinced of these things. Being that our parents are ordinarily our most significant authority figures, the things our parents or parental figures say to us as children have the most impact.

If you believe your oppressor, you tend to block learning before you even try. My low self-esteem prevented me from trying to reach goals that I believed were unattainable. The only jobs I applied for were those I was considered by others to be "suitable for". I did not have autonomy, self-confidence or self-determination. I relied on the support, advice and assistance of others. I believed others understood things I could not understand and I would try to hide this from them. My school friend Dalmas would often explain teaching instructions to me as I did not trust my own ability. He was a peer and not an adult or an authority figure, so I was able to receive the information more readily from him. Dalmas was not the one assimilating me and, although he was Caucasian, I did not view him as a superior like I did with respect to adult authority figures. 
Without him, I would have failed my classes. I was piggy-backing on his self-confidence, independence and self-determination as though I was only able to learn through others who accepted me as a person as opposed to as an object.

My low self-esteem, feelings of worthlessness, negative self-concept, hopeless outlook, and lack of direction all increased my anger exponentially. My inherent deference to authority and my lack of independence curbed what might otherwise have been an authentic and possibly important rebellion. I needed to release my pent up angst and take back an expression of my own autonomy, and perhaps even my own culture. Instead, I engaged in forms of destructive action (Freire, 1971, p. 155).

Those who engage in and are convicted of criminal forms of destructive action, such as myself, find themselves in an even more oppressive environment than the culture in which they originated. Canadian correctional philosophy (to use the expression loosely) requires the immersion of prisoner-subjects into an even more dominant culture of correctional programs and ideology that relies on the same banking education system that objectifies the now criminalized subject. It follows logically from the banking notion of consciousness that the "educator's [correctional program facilitator's] role is to regulate the way the world 'enters into' the students [prisoners]....The educated [rehabilitated] individual is the adapted person, because he or she is better 'fit' for the world" (Freire, 1971, p. 76).

With this said, immersing and assimilating people who commit crimes into a more oppressive atmosphere that is similar to what frustrated their potential as children, can only lead to further rebellion, indifference, alienation, and destruction. This can help explain the recidivism rate in Canada. Prisoners recognize the correctional banking education system of reform as more of the same authoritative oppression they initially rebelled against, only now it is being forced on the prisoners by a regime that has much more power than that of their grade-school teachers or parents. Prisoners can openly reject the correctional program initiatives and ethos by rebelling and refusing to participate in "voluntary" rehabilitative programs, but they must then suffer consequences ranging from loss of institutional pay, to withholding of transfers, to lesser security, to denial of conditional release and prolonged imprisonment. Alternatively, prisoners can fake it and "jump through the hoops", pretending to accept the correctional banking deposits when they secretly recognize its immersive and assimilationist 
logic. In either case, the banking system of rehabilitative programs in a correctional context fails miserably.

The challenges faced by correctional educators are great. Not only are the prisoner-students those who have rebelled to the point of transgressing laws, but most of them reject a banking system of education which they understand simply as being told what to do by people who are part of a system that is oppressing them; an oppression far greater than what they experienced throughout their childhood in primary and secondary school. A child, who has been oppressed and possibly abused throughout his or her formative years will resist more deposits and impositions through more education. Conversely, if willing to learn, lingering self-doubt and fear of failure will make it very difficult to enjoy learning. It is important to break through these barriers in order to learn. Moving beyond the psychological impediments to learning requires internalizing a self-concept that is contrary to believing that you are less than human and incapable.

After I came to prison I decided to get my grade 12 equivalency. First, I was subjected to a Scholastic Aptitude Test (SAT) to measure my grade level. When tested, the teacher told me that I was refused entry into the Adult Basic Education (ABE) Program because my SAT scores were too high. Instead, she offered me a job as her assistant for the ABE Program. I accepted and started taking classes in the humanities through Simon Fraser University's (SFU) Prison Education Program (PEP). I was performing stronger than I ever did in the primary/secondary or banking education system. Over time, I was eventually able to reject the labels of my childhood and started to accept that I was more than capable. This afforded me the freedom to continue to learn and I continued to do so with greater ease. Although it was not perceptible to me at the time, this contributed to changing my self-concept. In actuality, I never recognized that my problem was low self-esteem. I concentrated solely on learning and getting good grades without considering that there was a psychological benefit because healing from the past was also taking place at a subconscious level. My good grades were belying the things that had been drilled into me as a child and the culture I had been immersed into. This transformational process occurred without Dalmas telling me how to do the assignments.

I enjoyed my new found abilities so much that I would argue vigorously with my Philosophy 101: Critical Thinking instructor, Dr. Anthony Marcus, about modus ponens ${ }^{1}-$ a philosophical argument based on an absolutist 
premise that when a red horse is red, a blue horse is blue. I received an A- in the course. When I received an A+ on a short story in English 101 and an overall A for the semester, my doubt set in again. I began to think about the famous Stanford Prison Experiment where psychology professor Philip Zimbardo designed a mock prison on campus, assigning half of the volunteer college students to act as prisoners and half to act as prison guards. The experiment quickly spun out of control and was shut down. The student guards were abusing their power and the student prisoners were so psychologically affected that they started to believe that they were actually in prison. When I next sat with Dr. Marcus he asked me what my concern was. I responded smugly that I believed I had uncovered the truth, "You people from SFU are conducting a social experiment - you take a bunch of loser prisoners and give them high marks on their papers to study how those prisoners respond to being told they are smart". "No", he responded, "That is not what is going on here. The marks I give you are the same marks I would give any of my students on campus who complete assignments of this quality. I teach the exact same curriculum and I award the same work with the same grades". "Get outa town!", I blurted. "We're your guinea pigs like those university students in the Stanford Experiment". "No", he said again. "I don't think you yourself even realize all the things you did in this short story of yours. You used writing techniques I have not even taught you yet. In all seriousness, this short story is almost perfect, save for a couple minor typos".

I left that discussion unconvinced. I had never gotten better than a $\mathrm{C}+$ in grade school, and that only happened once or twice. For the most part, I barely passed. I decided to get a second opinion. I entered my short story in the Creative Writing category of the Prison Arts Foundation's annual competition. I won first place and was awarded a certificate and \$250, a complimentary copy of the issue, and a $\$ 50$ honorarium. Dr. Murphy was not lying. I was not a guinea pig in a social-science experiment. "What is going on here?", I wondered. As it turns out, the people I was to obey and revere as a child, the people I relied on for protection and truth about the world, had failed tragically. Although I cannot do anything to undo the course of events that led to my senseless violence against innocent people, problem-posing education in prison gave me an opportunity to grow and learn, as well as safely face the world and life's challenges if ever given a second chance. 
The banking system of education is an oppressive system that reduces students to nothing more than objects that exist to receive the information decided upon by the teacher/oppressor. The problem-posing system of education on the other hand is a liberating system that raises the students to the level of co-participants in the learning process and affords them the autonomy to decide for themselves how to view the knowledge shared. Students think for themselves as opposed to being told what to think.

Through dialogue, the teacher-of-the-students and the students-of-theteacher cease to exist and a new teacher-student with students-teachers emerges. The teacher is no longer merely the-one-who-teaches, but one who is himself taught in a dialogue with the students, who in turn while being taught also teach (Freire, 1971, p. 80).

This transformation reveals another benefit to employing the problemposing education system within the prison - the prisoner-student also ceases to exist. The prisoner-student-teachers are able to analyze and articulate their own circumstances, providing valuable insight through their lifeexperiences and the processes that led to their criminalization. Personal insights, introspective observations, and a forum to grow, learn and think for themselves are unobtainable through a banking system of education (or correctional therapeutic intervention).

No new knowledge comes out of telling prisoners who they are, what disorders they have (narcissistic personality or anti-social personality disorder, etc.), or what their predicted actuarial risk of recidivism is. Those truly committed to liberation must reject the banking concept in its entirety, adopting instead a concept of women and men as conscious beings and consciousness as intent upon the world. They must abandon the educational goal of deposit-making and replace it with the posing of the problems of human beings in their relation to the world (Freire, 1971, p. 79).

Two decades ago, one of the SFU-PEP professors, Dr. Stephen Duguid (1996) co-authored a paper on the benefits of prison education. The research demonstrated that the recidivism of prisoners who upgrade with post-secondary education after coming to prison is greatly reduced from those who do not upgrade. The paper argued that only about two percent of prisoners who upgrade with post-secondary education after coming to prison eventually recidivate. In the face of such evidence, one wonders why post-secondary education in Canada's prisons is not widespread today. 


\section{CONCLUSION}

Today, I can see a significant difference between how I was before coming to prison and how I am today. My self-concept has transformed. I am more willing to take on new challenges and explore uncharted waters. Looking back at my educational and vocational training, I cannot pinpoint when my self-image changed, but it did. The banking system of education employed by facilitators of so-called rehabilitative correctional programs or "therapeutic interventions" could never achieve or accomplish what the problem-posing system of the SFU PEP did. Despite its success, the Correctional Service of Canada (CSC) discontinued the SFU PEP program due to public complaints about prisoners being afforded a post-secondary education when the public is not. This argument misses the point. It costs on average $\$ 115,310$ to incarcerate someone in a federal prison in Canada for a year. If we are making an economic argument about prisoner education, then education is key to reducing costs. If prisoners can improve themselves and expand their world-view through education, they are less likely to reoffend upon release. According to the Corrections and Conditional Release Act (CCRA), CSC is tasked with preparing its prisoners for eventual release through program initiatives, and yet they folded to the public optics of "helping prisoners better themselves on the tax-payer's dime". Our choice as a society is between releasing people from prison without offering them opportunities to improve their chances at successful reintegration or investing in those opportunities that have been shown to work.

A problem-solving system of education not only helps to decrease recidivism, it also saves money. It not only saves on housing costs, but on policing costs, along with the judiciary resources that are required to investigate and prosecute recidivists that could have otherwise been productive members of society. This also demonstrates the importance of universal education in changing the course of an otherwise poorly developed worldview, which can lead to non-productivity at best and criminality at worst. In providing otherwise unskilled people with the tools they need to attain pro-social self-sufficiency, prison education can perhaps even contribute to creating a better world.

In closing, I want to give a shout out to Dr. Anthony Marcus, wherever he may be. "A red horse is only red and a blue horse is only blue if we are not all colour-blind". In other words, if we believe in the legislative mandate of 
the CSC, and if we are smart, then we should insist on forms of intervention that have been proven to work towards meeting that mandate. Postsecondary education has proven itself to contribute to significant change in the lives of prisoners, so it only makes sense to provide prisoners the opportunity to continue their education after completing their high-school equivalencies. We have to decide as a society whether we want prisoners to be better prepared for their release by way of programs that have proven to reduce the risk victimization of future crime or if prisoners should simply be warehoused and denied opportunities to learn, grow, and change.

\section{ENDNOTES}

1 Modus ponens (noun): The rule of logic which states that if a conditional statement (if $\mathrm{p}$ then q) is accepted, and the antecedent) holds, then the consequent (q) may be inferred - origin Latin, literally "mood that affirms" (Oxford Dictionary of English, Third Edition).

\section{REFERENCES}

Duguid, Stephen, Colleen Hawkey, and Ray Pawson (1996) "Using Recidivism to Evaluate Effectiveness in Prison Education Programs", Journal of Correctional Education, 47(2): 74-85.

Freire, Paulo (1971) Pedagogy of the Oppressed, New York: Bloomsbury Publishing. Fromm, Erich (2010) The Heart of Man, New York: American Mental Health Association

\section{ABOUT THE AUTHOR}

Vincent Charles Villebrun is incarcerated in a prison located in Québec, Canada. 